\title{
DETECTION OF AUTONOMIC DYSFUNCTIONS IN COMPLEX NEUROPSYCHOLOGICAL EXAMINATION OF NMU STUDENTS
}

\author{
Grigoriy Simonenko \\ Department of neurology \\ O. O. Bogomolets National Medical University \\ 13 Shevchenko blvd., Kyiv, Ukraine, 01601 \\ aleis@ukrpost.net
}

\begin{abstract}
According to the data of the world statistics there is observed the growth of autonomic dysfunctions. It is one of the main problems of clinical neurology: $12-25 \%$ of children and near $70 \%$ of adults suffers from these disorders.

Aim: diagnosing of autonomic dysfunctions in the contingent of students with the help of neuropsychological investigations.

Methods and materials: There were examined 1379 students of medical university. Self-appraisal autonomic system tone testing, Kerdo index, G. Dagnini-B.Aschner reflex and ortho-clinostatic sign were carried out on the first phase. For 157 students the Heart Rate Variability was investigated on the second phase. All students were tested by the Eysenck Personality Inventory on the third phase. 70 students (31 men, 39 women) were accordingly tested by the Minnesota Multiphasic Personality Inventory.

Results of research: Increasing of sympathetic part of the autonomic nervous system showed 221 (82.1\%) from 257 persons. Kerdo index was positive at 156 (60.7 \%) persons. Reactivity of the autonomic nervous system by the G.Dagnini-B.Aschner reflex showed sympathetic reaction in 133 (51.8\%) persons. Autonomic ensuring of the vital functions study by ortho-clinostatic sign also showed prevalence of the sympathetic reaction - 150 (58.4 \%) students. According to the RSAI, 5 marks (optimal) were showed in case of 52 (33.1\%) students. 4 marks - 68 (43.3\%) persons. 3, 2 and 1 marks were registered in case of 26 (16.6 \%) persons. Average SI was $168.47 \pm 16.42$. 4 marks of RSAI correlated with $\mathrm{SI}=137.29 \pm 5.75,2$ marks correlated with $\mathrm{SI}=508.12 \pm 32.12$. According to psychological tests, all students with extraversion reliably showed non-stability of the higher nervous action (14.38 \pm 017$)$, increased average T-marks of F-scale (77 \pm 1.949$), 9$-scale (71 \pm 1.553$)$ and 8 -scale (71 \pm 1.801$)$.

Conclusions: Indicators of autonomic tone, autonomic reactivity and autonomic activity ensuring showed prevalence of sympathicotonia in contingent of students. Heart Rate Variability investigation found dystonic disorders of autonomic nervous system of supra-segmental level mainly. Eysenck Personality Inventory found the prevalence of extraversion and non-stability of the higher nervous activity what may indicate further autonomic dysfunctions. Minnesota Multiphasic Personality Inventory testing revealed psychological disproportions with prevalence of hypomanic, paranoid, schizophrenic tendency. Psychologic affects cause further somatic complaints as manifestation of autonomic dysfunctions.
\end{abstract}

Keywords: autonomic status, autonomic dysfunction, Heart Rate Variability, EPI-test, MMPI-test, students.

\section{Introduction}

Syndrome of autonomic nervous system dysfunction is one of the main problems of clinical neurology. It is nearly $12-25 \%$ of children and to $70 \%$ of adults who suffer from these disorders. Vascular-autonomic dystonia prevalence in Ukraine was 1669.4 and morbidity was 393.7 on 100 thousands of population in 2009 [1].

Many psychosomatic diseases include autonomic dysfunctions [2, 3].

Level of functioning of the cardiovascular system is a very important indicator of adaptive possibilities and functioning of the autonomic nervous system (ANS) [4].

Among the non-invasive methods of cardiac autonomic regulation examination, heart beat rate variability (HBRV) is the most informative. Many parameters of it closely correlate one with another $[5,6]$.

Among other markers, the stress-index has a great place thanks to real indication of sympathetic system activation. Regulative systems activity index (RSAI) is an integrative parameter which shows exertion and possibilities of autonomic nervous system [7, 8].

Fluctuations of the blood pressure rate and initial forms of hypertension in young people also need HBRV examination [9, 10]. 
Early diagnosing of autonomic dysfunctions in case of children and adolescents allows to treat them more easy $[11,12]$.

Students are the very vulnerable contingent because it is a period of endocrine, psychic and social formation $[13,14]$.

It is time of formation of students' professional identity in the aspect of mental health stabilization, the period for development of basic sociogenic potentiality, as usually [15].

Autonomic disorders in children are closely connected with psychological peculiarities and need special tests for diagnostics [16].

\section{Aim of research}

To diagnose the autonomic dysfunctions in the contingent of students with the help of neuropsychological investigations.

\section{Methods and materials}

There were examined 1379 students of NMU: 439 men, 940 women, average age $20.7 \pm 0.20$ years. Self-appraisal autonomic system tone testing, Kerdo index, G.Dagnini-B.Aschner reflex and ortho-clinostatic sign carried out for 257 students on the first phase. For 157 students the Heart Rate Variability (HRV) was investigated on the second phase: 58 (37\%) men, $9963 \%$ ) women, average age $20.8 \pm 0.23$ years, control group 30 students. All students where tested by the EPI (Eysenck Personality Inventory) on the third phase [17, 18]. 70 students (31 men, 39 women) with control group of 25 students accordingly tested by the MMPI (The Minnesota Multiphasic Personality Inventory) [19, 20].

\section{Results of research}

Tone of the autonomic nervous system study showed the increase of its sympathetic part. According to self-appraisal testing, it took place in 221 (82.1\%) from 257 persons (127 (49.4\%) women and $84(50.6 \%)$ men). Kerdo index was positive in $156(60.7 \%)$ persons (109 (42.4 \%) women and $47(18.3 \%)$ men).

Reactivity of the autonomic nervous system, study by the G.Dagnini-B.Aschner reflex showed sympathetic reaction in 133 (51.8\%) persons (80 (31.1\%) women and 53 (20.6\%) men). Average percent of the pulse change was equal to $5.11 \pm 0.77(5.21 \pm 1.00$ of women and $4.93 \pm 1.19$ of men).

Autonomic ensuring of the vital functions study by ortho-clinostatic sign also showed the prevalence of the sympathetic reaction: 150 (58.4\%) students (96 (37.4\%) women and 54 (21.0 \%) men).

Heart rate variability investigation gave more characteristics of the autonomic nervous system state (Table 1).

The most important are two indicators: Regulation system activity index (RSAI) and Stress index (SI). According to the RSAI, 5 marks (optimal) were showed in case of $52(33.1 \%)$ students $(28(17.8 \%)$ women and $24(15.3 \%)$ men). Less normal were 4 marks - $68(43.3 \%)$ persons (46 (29.3\%) women and $22(14.0 \%)$ men). Increase of the functional effort (3, 2 and 1 marks) was registered in case of $26(16.6 \%)$ persons (15 (9.5\%) women and $11(7.1 \%)$ men). Extremal 0 marks were showed by $10(6.4 \%)$ students (9 (5.7 \%) women and 1 (0.6 \%) men).

SI is very different in groups of students with different RSAI (Fig. 1).

Average SI was $168.47 \pm 16.42$ (154.97 \pm 19.21 in women and 191.50 \pm 29.96 in men). These alterations became more in groups with less RSAI marks: so 4 marks correlated with $\mathrm{SI}=137.29 \pm 5.75$ (133.48 \pm 6.79 in women and $145.27 \pm 10.73$ in men), 2 marks correlated with $\mathrm{SI}=508.12 \pm 32.12$ $(456.44 \pm 29.63$ in women and $566.25 \pm 54.47$ in men).

EPI-testing showed the prevalence of extraversion and non-stability of the higher nervous action (Table 2).

All students with extraversion reliably showed non-stability of the higher nervous action (14.38 \pm 017$)$. It is more typical for women (14.97 \pm 0.19$)$. In case of ambiversion and introversion, non-stability registered only at women $(14.30 \pm 0.22$ and $14.06 \pm 0.26)$. 
70 students, tested by the MMPI, showed increased average T-marks of F-scale (77 \pm 1.949$)$, 9-scale (71 \pm 1.553$)$ and 8-scale (71 \pm 1.801$)$ (Table 3).

Table 1

Quantity of students according to the complex evaluation of the heart rate variability

\begin{tabular}{|c|c|c|c|}
\hline Characteristics & All students $(n=157)$ & Women $(n=99)$ & $\operatorname{Men}(n=58)$ \\
\hline Normocardia & $55(35.0 \%)$ & $30(19.1 \%)$ & $25(15.9 \%)$ \\
\hline Moderate tachycardia & $63(40.1 \%)$ & $41(26.1 \%)$ & $22(14.0 \%)$ \\
\hline Expressed tachycardia & $28(17.8 \%)$ & $20(12.7 \%)$ & $8(5.1 \%)$ \\
\hline Moderate bradycardia & $8(5.1 \%)$ & $4(2.5 \%)$ & $4(2.5 \%)$ \\
\hline Expressed bradycardia & $2(1.3 \%)$ & $2(1.3 \%)$ & - \\
\hline Moderate sinus arrhythmia & $138(87.9 \%)$ & $87(55.4 \%)$ & $51(32.5 \%)$ \\
\hline Expressed sinus arrhythmia & $4(2.5 \%)$ & $4(2.5 \%)$ & - \\
\hline Moderate disturbance of automatism & $2(1.3 \%)$ & - & $2(1.3 \%)$ \\
\hline Expressed disturbance of automatism & $8(5.1 \%)$ & $6(3.8 \%)$ & $2(1.3 \%)$ \\
\hline Stable rhythm & $4(2.5 \%)$ & $1(0.6 \%)$ & $3(1.9 \%)$ \\
\hline Moderate sympathicotonia & $21(13.4 \%)$ & $15(9.6 \%)$ & $6(3.8 \%)$ \\
\hline Expressed sympathicotonia & $8(5.1 \%)$ & $3(1.9 \%)$ & $5(3.2 \%)$ \\
\hline Moderate parasympathicotonia & $21(13.4 \%)$ & $15(9.6 \%)$ & $6(3.8 \%)$ \\
\hline Expressed parasympathicotonia & $7(4.5 \%)$ & $5(3.2 \%)$ & $2(1.3 \%)$ \\
\hline Amphotony & $93(59.2 \%)$ & $58(36.9 \%)$ & $35(22.3 \%)$ \\
\hline Central type dysregulation & $118(75.2 \%)$ & $75(47.8 \%)$ & $43(27.4 \%)$ \\
\hline Normal regulation & $31(19.7 \%)$ & $18(11.5 \%)$ & $13(8.2 \%)$ \\
\hline Parasympathetic prevalence dysregulation & $2(1.3 \%)$ & $2(1.3 \%)$ & - \\
\hline Sympathetic prevalence dysregulation & $1(0.6 \%)$ & - & $1(0.6 \%)$ \\
\hline Transition process & $4(2.5 \%)$ & $3(1.9 \%)$ & $1(0.6 \%)$ \\
\hline
\end{tabular}

Table 2

Quantity of EPI-tested students

\begin{tabular}{cccc}
\hline Sign & All students & Men & Women \\
\hline Extraversion & 546 & 164 & 382 \\
Introversion & 343 & 113 & 230 \\
Ambiversion & 490 & 162 & 328 \\
Increased excitability & 1007 & 269 & 738 \\
Normal excitability & 243 & 109 & 134 \\
Decreased excitability & 129 & 61 & 68
\end{tabular}




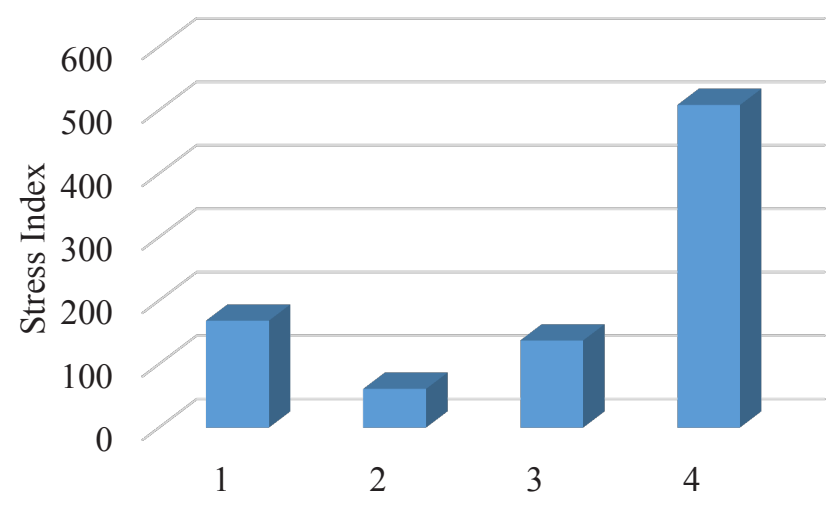

Fig. 1. Values of SI in students according to RSAI:

1 - All students; 2 - RSAI $=5 ; 3-\mathrm{RSAI}=4 ; 4-\mathrm{RSAI}=2$

Table 3

Average T-marks of all MMPI-tested students

\begin{tabular}{cccc}
\hline Scale & All students $(\mathbf{n}=\mathbf{7 0})$ & Men $(\mathbf{n}=\mathbf{3 1})$ & Women $(\mathbf{n}=\mathbf{3 9})$ \\
\hline L & $48 \pm 0.818$ & $46 \pm 1.155$ & $49 \pm 1.103$ \\
F & $77 \pm 1.949^{*}$ & $80 \pm 2.5483$ & $75 \pm 2.827^{*}$ \\
K & $51 \pm 0870$ & $49 \pm 1.340$ & $52 \pm 1.123$ \\
1 & $56 \pm 1.185$ & $54 \pm 1.622$ & $58 \pm 1.669$ \\
2 & $58 \pm 1.347$ & $54 \pm 1.460$ & $60 \pm 2.051$ \\
3 & $55 \pm 1.100$ & $52 \pm 1.459$ & $58 \pm 1.494$ \\
4 & $65 \pm 1.275$ & $66 \pm 1.784$ & $65 \pm 1.811$ \\
5 & $66 \pm 1.362$ & $76 \pm 1.412$ & $59 \pm 1.266$ \\
6 & $65 \pm 1.690$ & $67 \pm 2.168$ & $64 \pm 2.496$ \\
7 & $61 \pm 1.143$ & $59 \pm 1.508$ & $63 \pm 1.625$ \\
8 & $71 \pm 1.801$ & $72 \pm 2.462^{*}$ & $70 \pm 2.597$ \\
9 & $71 \pm 1.553$ & $76 \pm 2.064^{*}$ & $67 \pm 2.069$ \\
0 & $550.856 \pm$ & $55 \pm 1.297$ & $56 \pm 1.153$
\end{tabular}

Note: * - probability according to t-test $p<0.05$

These points were higher in men, including 5-scale (76 \pm 1.412$)$. There were 40 students with increased F-scale marks, 34 students with increased 9-scale marks, 32 students with increased 8 -scale marks, 24 students with increased 5-scale marks and 21 students with increased 6 -scale marks.

\section{Discussion}

Indicators of autonomic tone, autonomic reactivity and autonomic activity ensuring, along with the indicators of extraversion and non-stability of higher nervous activity showed the prevalence of sympathicotonia in the contingent of students. Most of them (61.68\%) were characterized by changing of the autonomic status with dominating of blood pressure hypotonia. It is possibly connected with the increase of the regulative systems effort.

161 volunteers were examined with the help of Heart Rate Variability investigation. As a result, dystonic disorders of autonomic nervous system with domination of supra-segmental level 
are registered. Integrative indicator of regulative system functioning was significantly decreased $(\mathrm{p}<0.05)$ in $69 \%$ of individuals with sympathetic adrenocortical stress. Stressing state of regulative system was registered in one third of students. Stress index, heart rate, mode, median, sigma and variation rage were more informative among the parameters of mathematical analysis of cardiointervals proportions. Stress-test has the special importance, it indicates the increasing centralization of cardiac rhythm regulation (effort of adaptation). $69 \%$ of students showed decreased active ortho-clinostatic probe, and $90 \%$ of individuals demonstrated decreased second phase. These data showed the autonomic regulation disorders with surplus involving of supra-segmental structures.

It appears that EPI-testing is effective for detection of the excitability higher nervous activity state. Its increased level (1007 persons, $58 \%$ of examined) may indicate further autonomic dysfunctions.

MMPI-testing revealed psychological disproportions with the prevalence of hypomanic, paranoid, schizophrenic tendency. Half of all examined students showed increased T-marks of 9 -scale (hypomania) - average mark $76 \pm 2.064$ in men. It means the acceleration of psychic activity with depression periods. Psychologic affects cause further somatic complaints as a manifestation of autonomic dysfunctions.

\section{Conclusions}

Complex achievement of these data may be used for early diagnosis of the autonomic dysfunctions. Most of students have some problems, which may be indicated by sympathicotonia (in ANS tone, ANS reactiveness and ANS insuring of activity), regulation system activity index and stress index, increased excitability higher nervous activity state, psychological disproportions with the prevailing increase of F, 9, 8 scales of MMPI-test.

Therefore, the algorithm of investigation consists of complex neurovegetative examination of students, which is advisable to start from EPI-testing and simple functional tests for estimation of autonomic tone, reactiveness, and support activities. HRV and MMPI-testing are clarifying methods. Significant deviation indexes from the average values, as the significant scattering of values according to different methods, testify some autonomic dysfunction.

\section{References}

[1] Hobzey, M., Mischenko, T., Zinchenko, O. (2010). State of neurological services in Ukaraine in 2009. News of Medicine and Pharmacy, 339, 69-79.

[2] Maclachlan, L. (2016). Causes and consequences of autonomic dysfunction in chronic fatigue syndrome. Newcastle University, Institute of Cellular Medicine, 262.

[3] Yaroshevskiy, A. (2010). Autonomic dysfunction and muscular-skeletal pain: the relationship and possibilities of non-pharmacological treatment. International Neurological Journal, 4, 62-70.

[4] Shlyk, N. I., Baevsky, R. M. (Eds.) (2008). Heart Rate Variability: Theoretical background and practical application. Izhevsk, 344.

[5] Ban, A., Paramonov, N., Zagorodniy, G., Ban, D. (2010). Analysis of the relationship of indicators of heart rate variability. Military medicine, 4, 21-24.

[6] Durnova, N., Dovgalevskiy, Ya., Burlaka, A., Kiselev, A., Furman, N. (2011). Interdependence of parameters of variational pulsometry, entropy of heart rate, temporal and spectral analyses of heart rate variability in normal state and in ischemic heart disease. Saratov Journal of Medical Scientific Research, 7 (3), 607-611.

[7] Simonenko, G. (2016). State of autonomic cardio-regulation in students of NMU. International Neurological Journal, 4, 60-65. doi: 10.22141/2224-0713.4.82.2016.77702

[8] Shakhanova, A. et. al. (2008). Functional and adaptive changes of cardiovascular system of students in dynamics of their education. Bulletin of the Adygeya State University, 9, 57-57.

[9] Negrusa, N. (2008). Diagnostic characteristics of variational pulsometry in people of young age with initial forms of hypertension. Saint Petersburg, 41. 
[10] Simonenko, G. (2017). Diagnosing of autonomic dysfunctions in medical students. Bulletin of Vinnitsa National Medical University, 21 (1), 116-119.

[11] Morozova, O., Yaroshevskyi, A., Zdybskyi, V. I. et. al. (2016). Vegetative dysfunction in general practice: ways of therapy optimization. Medicine of Ukraine, 5-6 (201-202), 40-46.

[12] Zavadenko, N., Nesterovskyi, Yu. (2012). Clinical manifestations and treatment of autonomic dysfunction in children and adolescents. Pediatria Journalnamed after G. N. Speransky, 91 (2), 92-102.

[13] Simonenko, G. (2016). Characteristics of the neuropsychological state of students suffered from autonomic dysfunction. Ukrainian Neurological Journal, 1, 89-92.

[14] Vinogradova, V. (2007). Problems of socialization of student's youth. Social Psychology, $150-151$.

[15] Zhiginas, N. (2011). Crisis of professional educational identity of the students as the problem of mental health. Saint Petersburg.

[16] Kuznetsova, E. (2011). Psychological peculiarities of children with functional disorders. St. Petersburg State University. Psychology of XXI century, 190-191.

[17] Eysenck, H., Wilson, G. (2012). How to measure personality. Moscow: Cogito-Center, 283.

[18] Simonenko, G. (2016). EPI in complex neuropsychological evaluation of neuropsychological state in students. International Medical Journal, 22 (2), 64-69.

[19] Sobchik, L. N. (2008). Standartizirovannyi mnogofaktornyi metod issledovaniya lichnosti SMIL [Standardized multifactorial method of studying personality SMIL]. Moscow: Publ. Borges, 250.

[20] Simonenko, G. (2016). Autonomic dysfunctions and medical students' MMPI profile peculiarities. Collection of scientific works of staff members of NMAPE, 25, 256-262. 